\title{
Concentrado protéico de resíduos da filetagem de tilápia-do-nilo (Oreochromis niloticus): caracterização físico-química e aceitação sensorial $^{1}$
}

\author{
Protein concentrate from the residues left after filleting Nile tilapia (Oreochromis \\ niloticus): physical-chemical characterization and sensory acceptance
}

\author{
Juliana Maria Aderaldo Vidal ${ }^{2 *}$, Maria do Carmo Passos Rodrigues ${ }^{3}$, Jorge Fernando Fuentes Zapata ${ }^{4}$ e Janaína \\ Maria Martins Vieira ${ }^{5}$
}

\begin{abstract}
Resumo - Este estudo objetivou o aproveitamento da carne mecanicamente separada (CMS) de resíduos da filetagem de tilápiado-nilo (Oreochromis niloticus Linnaeus, 1757) na obtenção de um concentrado protéico de tilápia (CPT) para o consumo humano, caracterizando-o quanto aos parâmetros físico-químicos e sensoriais. O CPT foi caracterizado quanto aos seguintes aspectos: rendimento, umidade, proteína, gordura, cinzas, atividade de água (Aw) e aceitação sensorial. O CPT apresentou rendimento de 18,34\%, baixos níveis de umidade e cinza e alto conteúdo protéico e lipídico, quando comparado à matéria-prima original (CMS) e baixa Aw. Na avaliação sensorial do CPT, a freqüência de aceitação dos provadores foi de $60,4 \%$ para a cor, $51,1 \%$ para o aspecto geral e $41,7 \%$ para o aroma. A descrição do aroma com termos como característico de pescado foi relatada por $44,2 \%$ dos provadores, sugerindo a necessidade de uma desodorização parcial do material, e indicando um equilíbrio em relação ao grupo dos provadores que não perceberam o odor característico. Esta pesquisa mostra agregação de valor a um material de descarte, gerando possibilidades de oferta de uma fonte proteica alternativa, de custo relativamente baixo.
\end{abstract}

Palavras-chave - Tilápia-Concentrado protéico. Pescado. Tilápia - Análise Sensorial.

\begin{abstract}
This study aimed to use mechanically separated mince (MSM) from the residues left after filleting Nile tilapia (Oreochromis niloticus Linnaeus, 1757) to obtain a protein concentrate for human consumption and to assess its proximal composition and sensory characteristics. Yield, proximal composition, water activity and sensory evaluation were analyzed on the dry TPC. The TPC has a yield of $18.34 \%$, and contained $1.38 \%$ moisture, $62.39 \%$ protein, $32.63 \%$ fat, $2.26 \%$ ash and had $0.16 \mathrm{Aw}$. Sensory evaluation of dry FPC powder expressed as frequency of acceptance by panelists was $60.4 \%$ for color, $51.1 \%$ for general appearance and $41.7 \%$ for aroma. Description of flavor using terms like "typical of fish" was reported by only $44.2 \%$ of the panelists, suggesting the need for a more efficient deodorizing process and showing a balance in relation to the group of panelists that did not notice the characteristic smell. The study shows the possibility of adding value to a residual food material offering an alternative source of protein at a relatively low cost.
\end{abstract}

Key words - Tilapia-Protein concentrate. Fish. Tilapia-Sensory analysis.

\footnotetext{
* Autor para correspondência

${ }^{1}$ Recebido para publicação em 09/10/2009; aprovado em 28/01/2011

Parte da dissertação de mestrado do primeiro autor, apresentada ao Programa de Pós-Graduação em Ciência e Tecnologia de Alimentos da UFC ${ }^{2}$ Curso de Engenharia de Pesca, Unidade Acadêmica de Serra Talhada/UFRPE, Fazenda Saco, s/n, Caixa Postal 063, Serra Talhada-PE, Brasil, 56.900-000, juliana@uast.ufrpe.br

${ }^{3}$ Departamento de Tecnologia de Alimentos, Centro de Ciências Agrárias/UFC, Av. Mister Hull, 2977, Bloco 857, Laboratório de Análise Sensorial, Alagadiço, Caixa Postal 12.168, Fortaleza-CE, Brasil,60.356-000, carminha@ufc.br

${ }^{4}$ Departamento de Tecnologia de Alimentos, Centro de Ciências Agrárias/UFC, Av. Mister Hull, 2977, Bloco 858, Alagadiço, Caixa Postal 12.168, Fortaleza-CE, Brasil, 60.356-000, zapata@ufc.br

${ }^{5}$ Programa de Pós-Graduação em Engenharia Química, Departamento de Engenharia Química/UFC, Campus do Pici, Fortaleza-Ce, Brasil, nainammv@hotmail.com
} 


\section{Introdução}

A piscicultura de água doce é a atividade que vem se mostrando mais promissora na produção de pescado, sendo a tilápia-do-nilo (Oreochromis niloticus Linnaeus, 1757) uma das espécies mais cultivadas mundialmente (JORY et al., 2000). O potencial aquícola da tilápia-donilo se deve à sua rusticidade, rápido crescimento, hábito alimentar onívoro, arraçoamento fácil e econômico, resistência a baixas concentrações de oxigênio dissolvido, além de apresentar carne de sabor apreciado e com poucas espinhas (KUBTIZA, 2000).

A tilápia é uma das espécies de peixe mais comercializada na forma de filé, apresentando um rendimento em filé de aproximadamente $33 \%$. No entanto, a maioria das unidades de beneficiamento de tilápia visa somente o aproveitamento do filé, descartando subprodutos comestíveis como o músculo abdominal ventral ("barriguinha"), o músculo hipaxial profundo e aparas do toalete final do filé (SOUZA; MACEDOVIEGAS, 2001).

São considerados resíduos de pescado carnes escuras, peixes de baixo tamanho comercial, resíduos obtidos dos processos de filetagem (VISENTAINER et al., 2003), cabeça, carcaças e vísceras. Os resíduos provenientes de frigoríficos processadores de peixe, principalmente de filetagem de tilápia representam 62,5 a $66,5 \%$ da matéria-prima (BOSCOLO et al., 2001).

No Brasil, o aproveitamento de resíduos da industrialização de pescado é considerado baixo, destinando-se, principalmente, ao preparo de farinhas de pescado. Normalmente, esses resíduos são acumulados em tanques sem receber qualquer tipo de tratamento, ocasionando uma má qualidade higiênica ou são descartados nas imediações do local de processamento, contribuindo para a contaminação ambiental (SEIBEL; SOUZA-SOARES, 2003).

A transformação destes resíduos em produtos para alimentação humana é uma ótima opção de renda para as indústrias, podendo aumentar sua lucratividade. Pessatti (2001) afirma que a grande inovação da tecnologia para recuperação dos resíduos de pescados foi o aparecimento de equipamentos capazes de separar o material muscular agregado às espinhas com facilidade.

O material muscular resultante dessa separação é conhecido como carne mecanicamente separada (CMS), que serve de base na elaboração de diversos produtos alcançando um significativo interesse em todo o mundo. O concentrado protéico de pescado (CPP), obtido a partir da CMS, pode se constituir em uma alternativa promissora por apresentar um alto valor nutritivo.
Os CPP são basicamente produtos desidratados e moídos, com conteúdo variável de proteínas, que podem apresentar ou não sabor e aroma de pescado, dependendo do método de obtenção utilizado (ORDÓÑEZ, 2005). As características fundamentais são o elevado valor biológico, o baixo custo e a fácil conservação (PRENTICE et al., 2002). Possui concentrações de proteínas superiores à do músculo de pescado (ORDÓÑEZ, 2005), apresenta grande capacidade de hidratação, o que facilita a sua inclusão em alimentos, além de uma alta digestibilidade, se comparado a outras proteínas, como a do ovo e a da carne bovina (PESSATTI, 2001).

Diante do exposto, este estudo teve como objetivo o aproveitamento da CMS de resíduos da filetagem de tilápia-do-nilo ( $O$. niloticus) na obtenção de um concentrado protéico de tilápia (CPT) para o consumo humano, caracterizando-o quanto aos parâmetros físicoquímicos e sensoriais.

\section{Material e métodos}

\section{Processamento do concentrado protéico de tilápia (CPT)}

Para obtenção do CPT utilizou-se CMS, obtida a partir de resíduos da filetagem de peixes da espécie tilápia-do-nilo $(O$. niloticus $)$ da linhagem tailandesa geneticamente pura.

O processo de obtenção da CMS foi realizado no Laboratório de Tecnologia do Pescado do Centro de Pesquisas em Aquicultura Rodolpho von Ihering do Departamento Nacional de Obras Contra as Secas (DNOCS), Pentecoste, CE, sob condições higiênicas satisfatórias. Para a recuperação da carne foi utilizada uma máquina despolpadora de pescado, marca High Tech, modelo HT 250. Aproximadamente $25 \mathrm{~kg}$ de CMS foram separados em porções de $1 \mathrm{~kg}$ e embaladas em sacos de polietileno, vedadas e congeladas em câmara frigorífica a $-20{ }^{\circ} \mathrm{C}$. A CMS congelada foi transportada em caixas térmicas para o Laboratório de Carnes e Pescado do Departamento de Tecnologia de Alimentos da Universidade Federal do Ceará.

Para o processo de obtenção do CPT, cerca de $25 \mathrm{~kg}$ de CMS foram divididos em porções de aproximadamente $5 \mathrm{~kg}$, totalizando-se cinco repetições do processo. A carne foi descongelada sob refrigeração, desembalada e submetida a dois ciclos de lavagens com água a aproximadamente $10{ }^{\circ} \mathrm{C}$, sob agitação e filtragem entre os ciclos de lavagem. Retirou-se a gordura sobrenadante e filtrou-se o material para retirada do excesso de água, usando-se um saco de microfibra de poliéster. 
O terceiro ciclo de lavagem foi realizado através de imersão em solução de $\mathrm{H}_{3} \mathrm{PO}_{4}(0,05 \%)$ na temperatura de $5{ }^{\circ} \mathrm{C}$, sob agitação durante 15 minutos para auxiliar na desodorização da carne e para alcançar o ponto isoelétrico da proteína miofibrilar $(\mathrm{pH} \pm 5)$. Em seguida, deixouse a carne decantar e retirou-se a gordura sobrenadante. Procedeu-se à filtragem em saco de microfibra de poliéster. O quarto ciclo de lavagem foi realizado seguindo o mesmo procedimento descrito para o primeiro e segundo ciclos de lavagem. Em todos os ciclos de lavagem, a proporção de líquido e carne foi de $3: 1$.

A carne lavada foi prensada manualmente e disposta em finas camadas em bandejas cobertas com papel alumínio e submetidas à secagem em estufa com circulação forçada de ar a $65^{\circ} \mathrm{C}$ por 15 horas.

$\mathrm{O}$ material seco foi submetido à lavagem com etanol, o excesso do álcool foi retirado através de filtragem e da secagem em estufa com circulação forçada de ar a $65^{\circ} \mathrm{C}$ por 3 horas.

Em seguida, o material foi triturado em processador doméstico e pesado para a determinação do rendimento. Foi acondicionado a vácuo em uma embalagem primária de polietileno e em uma embalagem secundária de polipropileno biorientado metalizado, para evitar a exposição à luz, sendo armazenado à temperatura ambiente.

\section{Análise fisíco-química}

As análises de umidade, proteína e gordura, foram realizadas de acordo com a metodologia da AOAC (1990). A atividade de água (Aw) foi determinada utilizando-se o equipamento AquaLab CX-2, da marca Decagon Devices Inc., com temperatura da amostra de $25^{\circ} \mathrm{C} \pm 2{ }^{\circ} \mathrm{C}$.

\section{Análise sensorial}

$\mathrm{Na}$ análise sensorial do CPT participaram 48 provadores não treinados, de ambos os sexos, dentre estudantes e funcionários da Universidade Federal do Ceará, com interesse em participar na avaliação deste tipo de produto. Foi perguntado a cada provador se concentrado protéico era um produto conhecido ou desconhecido e, se conhecido, se era saudável para o consumo.

As amostras de CPT foram servidas em placas de Petri e cada provador avaliou o aroma, a cor e o aspecto geral, através de escala hedônica estruturada de nove pontos $(1=$ desgostei muitíssimo; 5 nem gostei nem desgostei; 9 = gostei muitíssimo) (PERYAM; PILGRIM, 1954; STONE; SIDEL 1993). Em seguida cada provador descreveu o odor percebido.

\section{Análise estatística}

Os dados de caracterização físico-química do CPT foram submetidos à análise estatística descritiva, em que a média de cada triplicata foi considerada como uma observação.

Os dados sensoriais do CPT foram analisados através de análise estatística descritiva.

\section{Resultados e discussão}

\section{Rendimento e análises físico-químicas do concentrado protéico de tilápia (CPT)}

O valor médio (cinco repetições) de rendimento do processo de obtenção do CPT foi de 18,34\%. Esse valor foi similar ao encontrado por Silva et al. (2006), que avaliando o processo de obtenção de um isolado protéico desenvolvido a partir de pescado de baixo valor comercial, obtiveram um rendimento de $18 \%$. Pessatti (2001), elaborando um concentrado protéico de peixe, através de lavagens sucessivas com etanol, obteve um rendimento inferior $(14 \%)$ ao verificado no presente estudo. Desta forma, pode-se considerar o rendimento do CPT satisfatório, tendo se situado entre os valores médios observados na literatura.

Os resultados referentes aos teores de umidade, proteína, gordura e cinzas do concentrado protéico obtido a partir da CMS de resíduos da filetagem de tilápia-do-nilo estão expressos na Tabela 1.

Tabela 1 - Composição química e atividade de água do concentrado protéico de tilápia (CPT)

\begin{tabular}{lccccc}
\hline \multicolumn{1}{r}{ Variável } & Média* & $\sigma$ & Mínimo & Máximo & C.V. (\%) \\
\hline Umidade (\%) & 1,38 & 0,66 & 0,37 & 2,11 & 47,83 \\
Proteína (\%) & 62,39 & 2,01 & 59,55 & 64,35 & 3,22 \\
Gordura (\%) & 32,63 & 1,82 & 30,19 & 34,86 & 5,58 \\
Cinzas (\%) & 2,26 & 0,38 & 2,00 & 2,92 & 16,81 \\
Aw & 0,16 & 0,02 & 0,14 & 0,19 & 12,50 \\
\hline
\end{tabular}

*Média aritmética de cinco repetições em triplicata; $\sigma=$ Desvio padrão; C.V. (\%) = Coeficiente de variação 
O teor de umidade do CPT obtido a partir de CMS de resíduos da filetagem de tilápia-do-nilo variou entre $0,37 \%$ e $2,11 \%$, apresentando uma média de 1,38\% (TAB. 1), mostrando-se inferior ao relatado por Prentice et al. (2002), que foi de 7,0\% para o concentrado protéico obtido a partir de resíduos da filetagem da pescada (Macrodon ancylodon), com uso de máquina despolpadora, e próximo ao percentual observado por Pessatti (2001) em concentrado protéico obtido de amostras de filé de pescada de espécie não identificada $(2,5 \%)$.

O percentual de umidade do presente estudo também foi inferior ao observado por Silva et al. (2003) em sopa de peixe elaborada a partir de CMS de piranhapreta $(10,53 \%)$, seca em estufa com circulação forçada de ar a $60{ }^{\circ} \mathrm{C}$ por 18 horas.

Centenaro et al. (2007), estudando a complementação protéica de pão, elaboraram uma polpa seca de filé de cabrinha (Prionotus punctatus), através de três lavagens com água destilada e secagem em estufa de circulação forçada de ar a $60{ }^{\circ} \mathrm{C}$, por 7 horas. A umidade da polpa seca foi de $8,2 \%$, superior ao encontrado no presente trabalho.

A desidratação do CPT neste trabalho pode ser considerada bastante eficiente tendo em vista que Ogawa (1999) relata que o músculo do pescado fresco pode conter de 60 a $85 \%$ de umidade. Vila Nova et al. (2005), caracterizando a composição química de filé de tilápia $(O$. niloticus), reportaram um valor de $77,55 \%$ de umidade.

O conteúdo de proteína no CPT variou entre 59,55\% e $64,35 \%$, obtendo-se uma média de $62,39 \%$ (TAB. 1 ).

De acordo com os resultados apresentados por Kotaki (2005) o teor protéico da CMS de resíduos da filetagem de tilápia-do-nilo é de 9,6\%. Levando-se em consideração esse dado, os resultados do presente trabalho mostram que houve uma concentração de proteína de aproximadamente sete vezes em relação à CMS de tilápiado-nilo. Córser et al. (2000) e Justi et al. (2003) reportaram quantidades de proteína no filé de tilápia-do-nilo iguais a $18,34 \%$ e $18,2 \%$, respectivamente. Observa-se, portanto, que a efetiva remoção de água resultou na obtenção de um produto (CPT) com elevado percentual de proteína.

De acordo com Pessatti (2001), a concentração de proteína deve ser em média quatro vezes maior que o valor do teor protéico da matéria-prima, portanto o método de obtenção do CPT utilizado foi eficiente. O teor de proteína no concentrado protéico deste estudo foi bastante superior ao relatado por Pessatti, (2001) que foi de 34,7\%.

Murueta et al. (2007), estudando diferentes métodos de secagem no processo de produção de concentrados protéicos de nove espécies de peixes, verificaram que o conteúdo de proteína variou entre $57 \%$ e $77 \%$, sem que tenha havido diferença entre os diferentes métodos de secagem aplicados (liofilização, secagem a $65^{\circ} \mathrm{C}$ por $15 \mathrm{~h}$ e secagem a $100{ }^{\circ} \mathrm{C}$ por $12 \mathrm{~h}$ ).

García e Sobral(2005) encontraram uma quantidade de proteína igual a $80 \%$ para proteínas miofibrilares liofilizadas de tilápia-do-nilo. No entanto, MonterreyQuintero e Sobral (2000) verificaram valor igual a 93,22\% em proteínas miofibrilares liofilizadas de tilápia-donilo. Tais resultados foram superiores ao encontrado no presente trabalho.

O teor de proteínas do CPT foi bastante superior ao relatado por Stevanato et al. (2007) que avaliando a composição química de farinha de cabeça de tilápia-donilo destinada a elaboração de sopa verificaram o teor de proteína de $34,8 \% \pm 0,12 \%$.

Opercentual de gordura do CPT variou entre 30,19\% e $34,86 \%$ apresentando uma média de $32,63 \%$ (TAB. 1 ). $\mathrm{O}$ alto teor de gordura no CPT pode ser atribuído a vários fatores, dentre eles: i) a relação inversa bem caracterizada entre os teores de umidade e lipídios, em que o teor de umidade foi bastante reduzido e, consequentemente, o valor de gordura no CPT elevou-se; e ii) o CPT foi obtido de uma matéria-prima com considerável teor de gordura, pois de acordo com Kotaki (2005), o teor lipídico da CMS de tilápia-do-nilo é de aproximadamente $9,6 \%$ e na obtenção de CMS do presente estudo, foram utilizadas as partes ventrais do peixe, região onde se localizam os depósitos de gordura.

É importante salientar, que o alto teor de gordura no produto é de grande valia, considerando-se que a gordura de peixe é rica em ácidos graxos poli-insaturados os quais se destacam por apresentarem diversos efeitos benéficos à saúde humana, como diminuição dos riscos de doenças cardiovasculares, prevenção de câncer (MARTINO, 2003), diminuição nas taxas de colesterol no sangue (SIMOPOULOS, 2002) e benefícios à gravidez e saúde materno-infantil (DUSTAN et al., 2004).

Silva et al. (2003), elaborando sopa desidratada de peixe, a partir de CMS de piranha-preta determinaram na CMS 4,79\% de gordura. Após a secagem em estufa com circulação de ar esses autores obtiveram uma CMS seca com conteúdo lipídico de 18,86\%, praticamente quadruplicando o conteúdo lipídico da matéria-prima.

O teor de cinzas no CPT variou entre $2,00 \%$ e $2,92 \%$, observando-se uma média de 2,26\% (TAB. 1). Este resultado apresentou-se inferior ao descrito por Murueta et al. (2007) em estudo com concentrados protéicos de nove espécies de peixes obtidos através de diferentes processos de secagem. Esses pesquisadores encontraram variação no conteúdo de cinzas, entre as espécies de peixes estudados, 
de $8,15 \%$ a $20,27 \%$ em base seca, valores próximos aos encontrados por Monterrey-Quintero e Sobral (2000) em estudo com proteínas miofibrilares liofilizadas de tilápiado-nilo a serem utilizadas na elaboração de biofilmes $(1,69 \%$ de cinzas em base seca).

O valor médio da Aw do CPP, medido a $25^{\circ} \mathrm{C} \pm 2{ }^{\circ} \mathrm{C}$, foi de 0,16 , com coeficiente de variação de $12,50 \%$.

De acordo com Ferreira Neto et al. (2005), a maioria dos micro-organismos cresce em meio com atividade de água no intervalo entre 0,90 e 0,99 . Vários micro-organismos, às vezes, permanecem vivos por muito tempo em baixa $\mathrm{Aw}$, embora não se multipliquem nesse meio. A maioria das leveduras e fungos miceliais cresce em meio com Aw entre 0,86 e 0,88. Alguns fungos filamentosos podem crescer em meio com atividade de água de até 0,80 .

Dessa forma, a Aw no CPT apresentou-se baixa, portanto satisfatória, uma vez que os micro-organismos têm seu desenvolvimento condicionado à existência de água disponível, expressa em valores de Aw.

\section{Análise sensorial do concentrado protéico de tilápia (CPT)}

Opinião dos provadores sobre concentrados protéicos

Dentre os provadores, 56,25\% afirmaram conhecer concentrado protéico e 43,75\% desconheciam. Essa distribuição foi positiva por reduzir a influência da familiaridade com relação ao alimento. Dentre os que declararam conhecer concentrado protéico, 66,67\% concordaram que o consumo desse produto é saudável e $33,33 \%$ afirmaram ter dúvidas quanto a esse aspecto.

\section{Aceitação do concentrado protéico de tilápia (CPT)}

As medidas descritivas das variáveis aroma, cor e aspecto geral do CPT estão apresentadas na Tabela 2.
Através das medidas descritivas, observa-se que os três atributos avaliados apresentaram médias entre 5,17 e 5,88 correspondendo a "nem gostei/nem desgostei" e "gostei ligeiramente". Com relação à amplitude, o aroma alcançou o valor mínimo 1 (desgostei muitíssimo) e máximo 9 (gostei muitíssimo), enquanto os atributos cor e aspecto geral foram avaliados, respectivamente, com o mínimo 2 (desgostei muito) e 1 (desgostei muitíssimo) e máximo 8, correspondendo a gostei muito.

Com relação à frequência de aceitação dos atributos aroma, cor e aspecto geral (TAB. 3), 47,9\% das notas do aroma estiveram no grupo do desgostei (notas $<5$ ), ou seja, na faixa de rejeição; $10,4 \%$ das notas mostraram-se na região de indiferença (nota $=5$ ), ou seja, nem gostei/nem desgostei; e $41,7 \%$ estiveram no grupo do gostei (notas $>5$ ), e portanto na faixa de aceitação. Observa-se que o grupo de provadores apresentou-se dividido ao atribuir as notas para o aroma.

No atributo cor (TAB. 3), houve uma tendência para a região de aceitação, apresentado uma maior freqüência com $60,4 \%$ das notas compreendidas no grupo do gostei (notas $>5$ ); 20,8\% das notas no grupo do nem gostei/nem desgostei (notas $=5$ ), ou seja, na região de indiferença e 18,8\% apresentaram-se na faixa de rejeição (notas $<5$ ), portanto no grupo do desgostei.

Com relação ao aspecto geral (TAB. 3), 51,1\% das notas mostraram-se no grupo do gostei com valores superiores a 5, ou seja, na faixa de aceitação, 19,1\% apresentaram-se na região de indiferença (nem gostei/nem desgostei), com notas iguais a 5. Estiveram presentes no grupo do desgostei, $29,8 \%$ das notas, com valores inferiores a 5 , e, portanto, na região de rejeição.

Tabela 2 - Medidas descritivas das variáveis aroma, cor e aspecto geral do concentrado protéico de tilápia (CPT)

\begin{tabular}{lccc}
\hline \multirow{2}{*}{ Estatística } & & Variável & Aspecto Geral \\
\cline { 2 - 4 } & Aroma & Cor & 5,55 \\
\hline Média* & 5,17 & 5,88 & 6,00 \\
Mediana & 5,00 & 6,00 & 3,64 \\
Variância & 5,20 & 2,92 & 1,90 \\
Desvio Padrão & 2,28 & 1,70 & 1,00 \\
Mínimo & 1,00 & 2,00 & 8,00 \\
Máximo & 9,00 & 8,00 & \\
\hline
\end{tabular}

*Escala: 1 = desgostei muitíssimo; 5 = nem gostei, nem desgostei; 9 = gostei muitíssimo 
Tabela 3 - Distribuição de frequência da aceitação dos atributos aroma, cor e aspecto geral do concentrado protéico de tilápia (CPT) por notas da escala hedônica

\begin{tabular}{|c|c|c|c|c|c|c|}
\hline \multirow{2}{*}{ Escala* } & \multicolumn{2}{|c|}{--------------Aroma--------------- } & \multicolumn{2}{|c|}{------------------Cor---------------- } & \multicolumn{2}{|c|}{---------Aspecto Geral---------- } \\
\hline & Frequência & $\%$ & Frequência & $\%$ & Frequência & $\%$ \\
\hline$<5$ & 23 & 47,9 & 9 & 18,8 & 14 & 29,8 \\
\hline$=5$ & 5 & 10,4 & 10 & 20,8 & 9 & 19,1 \\
\hline$>5$ & 20 & 41,7 & 29 & 60,4 & 24 & 51,1 \\
\hline Total & 48 & 100,0 & 48 & 100,0 & 47 & 100,0 \\
\hline
\end{tabular}

*Escala: <5 - região de rejeição; $=5$ - indiferença; $>5$ - aceitação

Análise estatística descritiva das notas dadas por conhecimento de concentrados protéicos

Com o intuito de verificar se o fato de conhecer ou não um concentrado protéico influenciou na avaliação dos atributos aroma, cor e aspecto geral através da escala hedônica, realizou-se uma análise descritiva das notas atribuídas ao CPT.

Observa-se na Tabela 4 que, com relação ao aroma, os provadores que afirmaram conhecer concentrado protéico atribuíram em média 4,76, dentro da faixa de rejeição da escala hedônica. Vale ressaltar que muitos desses provadores conheciam outros tipos de concentrados protéicos mais comuns no mercado como o de soja, por exemplo, porém não conheciam CPP. Dessa forma, consideraram estranho o leve odor de peixe que o produto apresentava. Os provadores que afirmaram não conhecer concentrado protéico atribuíram uma nota média 5,48, entre nem gostei/nem desgostei (indiferente) e gostei ligeiramente, portanto não rejeitaram o aroma percebido.

Com relação à cor, os provadores que conheciam o produto concentrado protéico e os que o desconheciam atribuíram notas bem próximas, 5,89 e 5,86, respectivamente, correspondendo às notas da faixa de aceitação da escala hedônica. Essas médias encontradas são sugestivas da contribuição positiva da cor do CPP.

No aspecto geral, os provadores que afirmaram conhecer concentrado protéico atribuíram, em média, nota 5,76 , próxima à dos provadores que desconheciam concentrado protéico que foi de 5,38.

Tabela 4 - Medidas descritivas em função do conhecimento de concentrado protéico de peixe (CPP) pelos provadores

\begin{tabular}{|c|c|c|c|c|}
\hline \multirow{2}{*}{ Conhece CPP } & \multirow{2}{*}{ Estatística } & \multicolumn{3}{|c|}{------------------------------------Variável---------------------------------- } \\
\hline & & Aroma & Cor & Aspecto Geral \\
\hline \multirow{8}{*}{$\operatorname{Sim}$} & Média & 4,76 & 5,86 & 5,76 \\
\hline & Mediana & 4,00 & 6,00 & 6,00 \\
\hline & Variância & 6,49 & 3,52 & 3,59 \\
\hline & Desvio Padrão & 2,54 & 1,87 & 1,89 \\
\hline & Mínimo & 1,00 & 2,00 & 1,00 \\
\hline & Máximo & 9,00 & 8,00 & 8,00 \\
\hline & Amplitude & 8,00 & 6,00 & 7,00 \\
\hline & $\mathrm{N}$ & 21,00 & 21,00 & 21,00 \\
\hline \multirow{8}{*}{ Não } & Média & 5,48 & 5,89 & 5,38 \\
\hline & Mediana & 5,00 & 6,00 & 5,50 \\
\hline & Variância & 4,18 & 2,56 & 3,76 \\
\hline & Desvio Padrão & 2,04 & 1,60 & 1,94 \\
\hline & Mínimo & 2,00 & 3,00 & 2,00 \\
\hline & Máximo & 9,00 & 8,00 & 8,00 \\
\hline & Amplitude & 7,00 & 5,00 & 6,00 \\
\hline & $\mathrm{N}$ & 27,00 & 27,00 & 26,00 \\
\hline
\end{tabular}




\section{Descrição do aroma percebido no concentrado protéico de tilápia}

Solicitou-se aos provadores que descrevessem o aroma percebido no CPT. Os termos citados e sua freqüência encontram-se na Tabela 5.

Tabela 5 - Termos descritivos do aroma percebido no concentrado protéico de tilápia $(\mathrm{CPT})$

\begin{tabular}{lcr}
\hline \multicolumn{1}{c}{ Aroma percebido } & Frequência & \multicolumn{1}{c}{$\%$} \\
\hline Agradável & 2 & 3,3 \\
Barra de cereal, Cereal & 3 & 4,9 \\
Desagradável & 1 & 1,6 \\
Doce & 8 & 13,1 \\
Farinha láctea & 5 & 8,2 \\
Gordura, Óleo, Ranço & 4 & 6,5 \\
Ovo & 5 & 8,2 \\
Peixe, Frutos do mar, Peixe & & \\
cozido, Bacalhau, Ração de peixe, & 27 & 44,2 \\
Escamas & & \\
Ração animal, Ração de gato & 2 & 3,2 \\
Soja & 1 & 1,6 \\
Suave & 1 & 1,6 \\
Não respondeu & 2 & 3,3 \\
\hline \multicolumn{1}{c}{ Total } & 61 & 100,0 \\
\hline
\end{tabular}

Verifica-se que o aroma de peixe foi percebido por $44,2 \%$ dos provadores, que o descreveram como: frutos do mar, peixe, bacalhau, peixe cozido, escamas ou ração de peixe. Pessatti (2001) elaborou um concentrado protéico de peixe através de lavagens sucessivas com etanol e relatou que o odor foi caracterizado como de frutos do mar, de modo similar à descrição dos provadores deste estudo.

Observa-se que $55,8 \%$ dos consumidores não perceberam o odor de peixe, resultado bastante satisfatório, haja vista este percentual ter sido superior ao dos consumidores que perceberam o odor de peixe $(44,2 \%)$. Esses resultados sugerem, portanto, que a desodorização do CPT com lavagens de água e solução de $\mathrm{H}_{3} \mathrm{PO}_{4}$ foi parcial. $\mathrm{O}$ termo farinha láctea citado por $8,2 \%$ dos provadores provavelmente pode estar associado à aparência do CPT similar a essa farinha.

\section{Conclusões}

1. O concentrado protéico de tilápia (CPT) apresentou baixos níveis de umidade e cinza e alto conteúdo protéico e lipídico, quando comparado à matéria-prima original constituída de carne mecanicamente separada (CMS). O CPT mostra boa estabilidade com base na sua baixa atividade de água;

2. O CPT alcançou aceitabilidade entre nem gostei/nem desgostei e gostei ligeiramente em aroma, cor e, aspecto geral, indicando possibilidade de utilização como ingrediente alimentício;

3. O método aplicado para obtenção do CPT permitiu que o material fosse desodorizado parcialmente;

4. O aproveitamento da CMS obtida dos resíduos da filetagem de tilápia-do-nilo (Oreochromis niloticus Linnaeus 1757), como matéria-prima na obtenção de CPT agregou valor a um material de descarte, trazendo contribuição para a redução da poluição ambiental e oferecendo uma alternativa para uso alimentar de custo relativamente baixo.

\section{Agradecimentos}

À Fundação Cearense de Apoioao Desenvolvimento Científico e Tecnológico (FUNCAP), pela concessão da bolsa de estudo e ao Departamento Nacional de Obras Contra as Secas (DNOCS), Unidade Pentecoste - CE, pela doação da matéria-prima, disponibilidade dos seus laboratórios e pelo apoio.

\section{Referências}

ASSOCIATION OF OFFICIAL ANALYTICAL CHEMISTS. Official methods of analysis. $15^{\text {th }}$ ed. Virginia: AOAC, 1990. $1214 \mathrm{p}$.

BOSCOLO, W. R. et al. Desempenho e características de carcaça de machos revertidos de tilápia do Nilo (Oreochromis niloticus), linhagens tailandesa e comum, nas fases inicial e de crescimento. Revista Brasileira de Zootecnia, v. 30, n. 05, p. 1391-1396, 2001.

CENTENARO, G. S. et al. Enriquecimento de pão com proteínas de pescado. Ciência e Tecnologia Alimentos, v. 27, n. 03, p. 663-668, 2007.

CÓRSER, P. I. et al. Análisis proximal, perfil de ácidos grasos, aminoácidos esenciales y contenido de minerales en doce especies de pescado de importancia comercial en Venezuela. Archivos Latinoamericanos de Nutrición ALAN, v. 50, n. 02, 2000.

DUSTAN, J. A.; ROPER, J.; MITOULAS, L. The effects of supplementation with fish oil during pregnancy on breast milk immunoglobulin A, soluble CD14, cytokine levels and fatty acid composition. Clinical \& Experimental Allergy, v. 34, n. 08, p. 1237-1242, 2004. 
FERREIRA NETO, C. J.; FIGUEIRÊDO, R. M. F.; QUEIROZ, A. J. M. Avaliação sensorial e da atividade de água em farinhas de mandioca temperadas Ciência e Agrotecnologia, v. 29, n. 4, p. $795-802,2005$.

GARCÍA, F. T.; SOBRAL, P. J. A. Effect of the thermal treatment of the filmogenic solution on the mechanical properties, color and opacity of films based on muscle protein of two varieties of Tilapia. LWT - Food Science and Technology, v. 38, n. 03, p. 289-296, 2005.

JORY, D. E.; ALCESTE, C.; CABRERA, T. R. Mercado y comercialización de tilapia en los Estados Unidos de Norteamérica. Panorama Acuícola, v. 05, n. 05, p. 50-53, 2000.

JUSTI, K. C. et al. The influence of feed supply time on the fatty acid profile of Nile tilapia (Oreochromis niloticus) fed on a diet enriched with n-3 fatty acids. Food Chemistry, v. 80, p. 489-493, 2003.

KOTAKI, S. H. Utilização da carne mecanicamente separada (CMS) da carcaça de tilápia (Oreochromis niloticus) para a elaboração de lingüiça de peixe. 2005. 94f. Dissertação (Mestrado em Engenharia de Pesca) - Universidade Federal do Ceará, Fortaleza. KUBITZA, F. Tilápia: tecnologia e planejamento na produção comercial. Jundiaí, 2000. 285 p.

MARTINO, R. C. Exigências e cuidados da adição de lipídios em rações para peixes e a sua importância para o homem. Panorama da Aqüicultura, Rio de Janeiro, p. 58-60, jan./fev. 2003.

MONTERREY-QUINTERO, E. S.; SOBRAL, P. J. A. Preparo e caracterização de proteínas miofibrilares de tilápia-doNilo para elaboração de biofilmes. Pesquisa Agropecuária Brasileira, v. 35, n. 01, p. 179-189, 2000.

MURUETA, J.H. C.; TORO, M de los A. N. del; CARRREÑO, F. G. Concentrates of fish protein from bycatch species produced by various drying processes. Food Chemistry, v. 100, p. 705-711, 2007.

OGAWA, M. Química do pescado: Umidade e Proteína. In: OGAWA, M.; MAIA, E. L. (Eds), Manual de Pesca. v. I: Ciência e Tecnologia. São Paulo: Varela, 1999. Cap. 4, p. 29-48.

ORDÓÑEZ, J. A. et al. Tecnologia de alimentos: alimentos de origem animal. Porto Alegre: Artmed, 2005. v. 2. p. 279.

PERYAM, D. R.; PILGRIM, F.J. Hedonic scale method of measuring food preferences. Food Tecnhology, v. 11, n. 09, p. 9-14, 1954.

PESSATTI, Marcos Luiz (Coord.). Aproveitamento dos subprodutos do pescado. Itajaí: MAPA/UNIVALI, 2001, 27 p.
PRENTICE, C. et al. Processo de obtenção de um concentrado protéico de resíduos da industrialização do pescado. In: CONGRESSO BRASILEIRO DE CIÊNCIA E TECNOLOGIA DE ALIMENTOS. 17., 2002, Fortaleza-CE. Resumos... Fortaleza: SBCTA, 2002. v. 3, p. 11.106.

SEIBEL N. F.; SOUZA-SOARES, L. A. Produção de silagem química com resíduos de pescado marinho. Brazilian Journal of Food Technology, v. 06, n. 02, p. 333-337, 2003.

SILVA, M. A. B.; LESSI, E.; JESUS, R. S.; FALCÃO, P. T. Utilização de piranha-preta Serrasalmus rhombeus para elaboração de sopas de peixe. In: CONGRESSO BRASILEIRO DE ENGENHARIA DE PESCA, 13., 2003, Porto Seguro/BA. Resumos... Porto Seguro: AEP-BA, 2003. p. 1122.

SILVA, M. C. et al. Avaliação do processo de obtenção de um isolado protéico desenvolvido a partir de pescado de baixo valor comercial In: SEAFOOD 2006 INOVAÇÕES TECNOLÓGICAS E VALOR AGREGADO NA TECNOLOGIA DO PESCADO: PESQUISAS BRASILEIRAS, 2006, São Paulo - SP. Resumos... São Paulo, 2006.

SIMOPOULOS, A. P. Omega-3 fatty acids in inflammation and autoimmune diseases. Journal of the American College of Nutrition, v. 21, n. 06, p. 495-505, 2002.

SOUZA, M. L. R.; MACEDO-VIEGAS, E. M. Comparação de quatro métodos de filetagem utilizados para a tilápia do Nilo (Oreochromis niloticus) sobre o rendimento do processamento. Infopesca International, p. 26-31, 2001.

STEVANATO, F. B. et al. Avaliação química e sensorial da farinha de resíduo de tilápias na forma de sopa Ciência e Tecnologia de Alimentos, v. 27 n. 03, p. 567-571, 2007.

STONE, H.; SIDEL, J. B. Sensory evaluation practices. $2^{\text {nd }}$ ed. Redwood City, CA: Tragon Corporation, 1993.

VILA NOVA, C. M. V. M.; GODOY, H. T.; ALDRIGUE. M. L. Composição química, teor de colesterol e caracterização dos lipídios totais de tilápia (Oreochromis niloticus) e pargo (Lutjanus purpureus). Ciência e Tecnologia de Alimentos, v. 25, n. 03, p. 430-436, 2005.

VISENTAINER, J. V. et al. Efeito do tempo de fornecimento de ração suplementada com óleo de linhaça sobre a composição físico-química e de ácidos graxos em cabeças de tilápia do Nilo (Oreochromis niloticus). Ciência e Tecnologia de Alimentos, v. 23, n. 03 , p. $478-484,2003$. 